University for Business and Technology in Kosovo

UBT Knowledge Center

UBT International Conference

2018 UBT International Conference

Oct 27th, 1:30 PM - 3:00 PM

\title{
Designing a controller via Simulated Annealing
}

\author{
Zemerart Asani \\ University of Tetova, zemerart.asani@hotmail.com
}

Selvet Rexhepi

Follow this and additional works at: https://knowledgecenter.ubt-uni.net/conference

Part of the Robotics Commons

\section{Recommended Citation}

Asani, Zemerart and Rexhepi, Selvet, "Designing a controller via Simulated Annealing" (2018). UBT International Conference. 337.

https://knowledgecenter.ubt-uni.net/conference/2018/all-events/337

This Event is brought to you for free and open access by the Publication and Journals at UBT Knowledge Center. It has been accepted for inclusion in UBT International Conference by an authorized administrator of UBT Knowledge Center. For more information, please contact knowledge.center@ubt-uni.net. 


\title{
Designing a controller via Simulated Annealing
}

\author{
Zemerart Asani \\ Department of Mechatronics, Faculty of Applied Sciences, University of Tetova, Macedonia \\ zemerart.asani@hotmail.com
}

\begin{abstract}
With Proportional-Integral-Derivative (PID) controllers being widely used in industry for optimum solutions. Optimization of the PID controller is an important problem in Control Engineering. Therefore, in this paper work we have implemented Simulated Annealing to tune the controller parameters. Optimizing the controller parameters on the basis of the Simulated Annealing algorithm, based on criteria defined using an objective function, allows us to find optimal solutions for the controller parameters that give us minimum error. In terms of performance, the PID controller designed with Simulated Annealing gives us great results with regard to the rise time, settling time, overshoot and steady-state error. Simulated Annealing (SA) is a meta-heuristic method which is used to find solutions in a large search space. It is inspired by a physical process, specifically based on annealing in metallurgy. In annealing the slow cooling of the material increases the size of its crystals and thus reduces defects. SA is dependent on internal thermodynamic energy. When it is implemented for the PID controller problem the algorithm searches for the minimal energy, respectively the minimal error. The case study of tuning the PID for the Mechatronics system verifies that this method can be used for this purpose and great performance of the system can be achieved.
\end{abstract}

Keywords: Simulated Annealing (SA), PID controller tuning, Mechatronics systems, Optimization 


\section{Introduction}

In industrial systems, when a closed loop system control is being used, mostly the PID is used as a controller. The PID controller has three gains, the proportional $\left(K_{P}\right)$, the derivative $\left(K_{d}\right)$ and the integral gain $\left(K_{i}\right)$ [3]. The error $e(t)$ is the difference between the set-point and the output of the plant. The controller acts by correcting the error in the system, and therefore will adjust the plant output. The proportional part is responsible to follow the desired set-point, while the integral part account for the accumulation of past errors and derivative accounts for the rate of change of error in the process[7].

The PID controller has the following general form[3]:

$$
g_{c}(t)=K_{P} e(t)+K_{i} \int_{0}^{t} e(t) d t+K_{d} \frac{d e(t)}{d t} .
$$

In the Laplace domain the afore equation for the PID controller is as follows:

$$
G_{c}(s)=K_{P}+K_{i} \frac{1}{s}+K_{d} s .
$$

These three parameters of the PID controller can be tuned via the algorithm that is based on the physical process of cooling, particularly the simulated annealing optimization technique. The optimization leads to the desired performance depending on the requirements of the system specified by the objective function.

The structure of the control system is shown in the figure below.

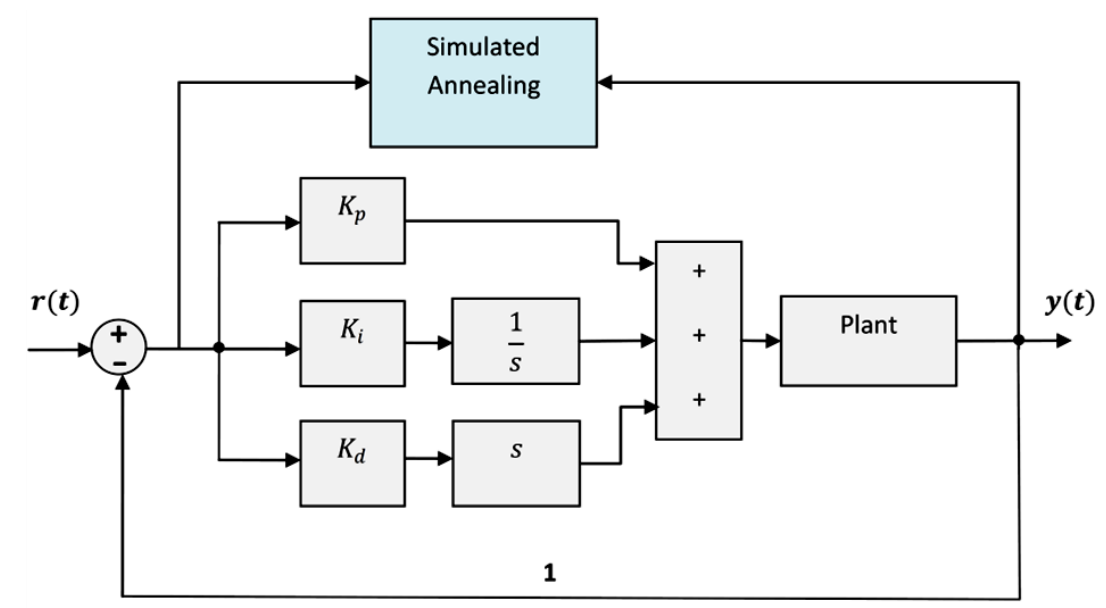

Fig. 1. Structure of SA-PID controller

\section{Simulated annealing (Boltzmann Annealing)}

The simulated annealing algorithm (SA) is based on the model of the physical process of cooling, particularly on annealing in metallurgy: slow cooling of material to increase 
size of its crystals, thus reducing the defects. It is dependent on the internal thermodynamic energy.

Modeled by Boltzmann distribution of energy states (Ludwig Boltzmann 1868, Josiah Willard Gibbs 1902). The algorithm searches for minimal energy [2].Probability for acceptance of new cost-function is based on the chances of obtaining a new state with energy $E_{k+1}$ relative to a previous state $E_{k}$ [4]. The law of thermodynamics state that at temperature, $t$, the probability of an increase in energy of magnitude, $\Delta \mathrm{E}$, is given by the following equation [6]:

$$
p(\Delta \mathrm{E})=\frac{e^{-E_{k+1} / T}}{e^{-E_{k+1} / T}+e^{-E_{k} / T}}=\frac{1}{1+e^{\Delta \mathrm{E} / T}} \cong e^{-\Delta \mathrm{E} / T} .
$$

Where $\Delta \mathrm{E}=E_{k+1}-E_{k}$ is the difference in energy between the present and the previous values of the energies (cost functions) for a physical problem[4].

Pseudo-code of Simulated Annealing[2]:

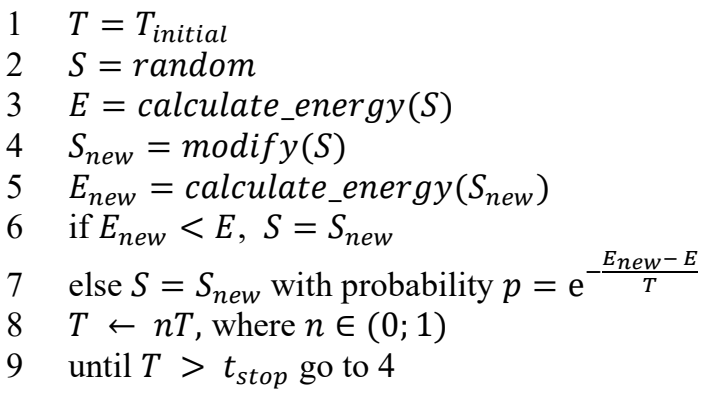

\subsection{Fast Annealing (FA)}

In optimization problems the Cauchy distribution works better than Boltzmann form of the Simulated Annealing and has many advantages compared to BA. The Cauchy distribution is represented as follows [4]:

$$
p(\Delta \mathrm{x})=\frac{T}{\left(\Delta \mathrm{x}^{2}+\mathrm{T}\right)^{(\mathrm{D}+1) / 2}} .
$$

The Fast Annealing (FA) method gives an annealing schedule exponentially faster than with the Boltzmann Annealing[4].

The objective is optimization of the controller based on objective function objective function $\boldsymbol{F}(\boldsymbol{y}), \boldsymbol{F} \in \mathcal{F}$ with respect to a group of variables known as objective parameters $\boldsymbol{y}:=\left(\boldsymbol{y}_{1}, \boldsymbol{y}_{2}, \boldsymbol{y}_{3}, \ldots\right)$. If we have the objective function $\boldsymbol{F}$ to be optimized, $\boldsymbol{F}(\boldsymbol{y}) \rightarrow \boldsymbol{o p t}$., $\boldsymbol{y} \in \mathcal{Y} . \boldsymbol{F}$ is the objective function, respectivelly a real-valued function on the search space, $\boldsymbol{Y} \subset \boldsymbol{R}^{n}$.

The search space will be defined by the upper and lower bounds for each parameter of the controller, where the Simulated Annealing (SA) searches for the best fitness. 
Therefore, we define our optimization problem in the following manner[5].

$\left\{P I D \in R^{n}: P I D_{m, \ldots, o}\left[\right.\right.$ lower $_{m, \ldots o}$, upper $\left.\left._{m, \ldots o}\right], m, n, o=1,2,3, \ldots n\right\}$ where $P I D=$ $\left[K_{p}, K_{i}, K_{d}\right]$.

$$
\min \underset{\left\{K_{p}, K_{i}, K_{d}\right\}}{F}, \text { for } K_{p}, K_{i}, K_{d} \in \mathcal{Y} .
$$

\section{The objective functions}

There are different perfomance indices. In our paper work we are going to implement integral absolute error (IAE), integral of the squared error value (ISE), integral time absolute error (ITAE), integral of the time weighted square error value (ITSE), mean square error (MSE), and the linear quadratic regulator (LQR) as an hybrid objective function. 
Integral of the absolute error value (IAE):

$I A E=\int_{o}^{T}|e(t)| d t=\sum|r(t)-y(t)| \rightarrow \min \sum_{K_{p}, K_{d}, K_{i}}|r(t)-y(t)|$

$=\min \sum_{K_{p}, K_{d}, K_{i}}|e(t)| d t$.

Integral of the squared error value (ISE):

$I S E=\int_{o}^{T}[r(t)-y(t)]^{2} d t=\int_{o}^{T} e(t)^{2} d t=\sum[e(t)]^{2} d t$
$=\min \sum_{K_{p}, K_{d}, K_{i}}[e(t)]^{2} d t$.

Integral of the time weighted squared error value (ITSE):

$$
\begin{aligned}
& \operatorname{ITSE}=\int_{0}^{T} t[e(t)]^{2} d t=\sum t[r(t)-y(t)]^{2} d t \rightarrow \min \sum_{K_{p}, K_{d}, K_{i}} t[r(t)-y(t)]^{2} d t \\
= & \min \sum_{K_{p}, K_{d}, K_{i}} t[e(t)]^{2} d t .
\end{aligned}
$$

Linear Quadratic Regulator (LQR) cost function:

$$
\begin{array}{r}
L Q R=\int_{o}^{t}\left[x^{T} Q x+u^{T} R u\right] d t=\sum\left[x^{T} Q x+u^{T} R u\right] d t \\
\rightarrow \min \sum_{K_{p}, K_{d}, K_{i}}\left[x^{T} Q x+u^{T} R u\right] d t .
\end{array}
$$

Integral of the time weighted absolute error (ITAE):

$$
\begin{aligned}
& I T A E=\int_{o}^{T} t|e(t)| d t=\sum t|r(t)-y(t)| \rightarrow \min \sum_{K_{p}, K_{d}, K_{i}} t|r(t)-y(t)| \\
& =\min \sum_{K_{p}, K_{d}, K_{i}} t|e(t)| d t .
\end{aligned}
$$

Mean square error (MSE):

$M S E=\frac{1}{n} \sum_{i=1}^{n}[e(t)]^{2} \rightarrow \min \frac{1}{n} \sum_{K_{p}, K_{d}, K_{i}}[e(t)]^{2}$.

\section{Tuning the controller for the mechatronics system}

In order to demonstrate the effectiveness of this approach we are going to try the algorithm by tuning the PID controller parameters for a mechatronics system. From the control perspective we have to design a motion control system which is required to provide a motion control with a precise end motion[1]. The mathematical model (the transfer function in the Laplace domain) for the mechatronics system is [1]: 


$$
G(s)=\frac{0.0571}{s^{2}+0.6 s+0.3432}
$$

Table 1. Results from optimization

\begin{tabular}{|c|c|c|}
\hline & BA & FA \\
\hline IAE & $\mathrm{Kp}=30.87 ; \mathrm{Kd}=128.56 ; \mathrm{Ki}=78.87$ & $\begin{array}{c}\mathrm{Kp}=618.04 ; \mathrm{Kd}=999.21 \\
\mathrm{Ki}=305.37\end{array}$ \\
\hline ISE & $\begin{array}{c}\mathrm{Kp}=44.13 ; \mathrm{Kd}=130.78 \\
\mathrm{Ki}=51.65\end{array}$ & $\begin{array}{c}\mathrm{Kp}=584.28 ; \mathrm{Kd}=607.32 ; \\
\mathrm{Ki}=220.56\end{array}$ \\
\hline ITSE & $\begin{array}{c}\mathrm{Kp}=92.74 ; \mathrm{Kd}=72.79 \\
\mathrm{Ki}=50.51\end{array}$ & $\begin{array}{c}\mathrm{Kp}=374.41 ; \mathrm{Kd}=852.51 ; \\
\mathrm{Ki}=131.81\end{array}$ \\
\hline ITAE & $\begin{array}{c}\mathrm{Kp}=97.58 ; \mathrm{Kd}=25.52 \\
\mathrm{Ki}=129.92\end{array}$ & $\begin{array}{c}\mathrm{Kp}=293.76 ; \mathrm{Kd}=476.03 ; \\
\mathrm{Ki}=170.88\end{array}$ \\
\hline LQR & $\begin{array}{c}\mathrm{Kp}=49.74 ; \mathrm{Kd}=53.11 \\
\mathrm{Ki}=221.95\end{array}$ & $\begin{array}{c}\mathrm{Kp}=553.34 ; \mathrm{Kd}=95.61 \\
\mathrm{Ki}=343.32\end{array}$ \\
\hline MSE & $\begin{array}{c}\mathrm{Kp}=65.74 ; \mathrm{Kd}=203.88 \\
\mathrm{Ki}=0.75\end{array}$ & $\begin{array}{c}\mathrm{Kp}=402.17 ; \mathrm{Kd}=999.59 ; \\
\mathrm{Ki}=242.74\end{array}$ \\
\hline \multicolumn{3}{|c|}{ Stopping criteria: 500 iterations } \\
\hline
\end{tabular}

Where the search space is defined as $0 \leq K_{p} \leq 1000 ; 0 \leq K_{d} \leq 1000 ; 0 \leq K_{i} \leq$ 1000 .

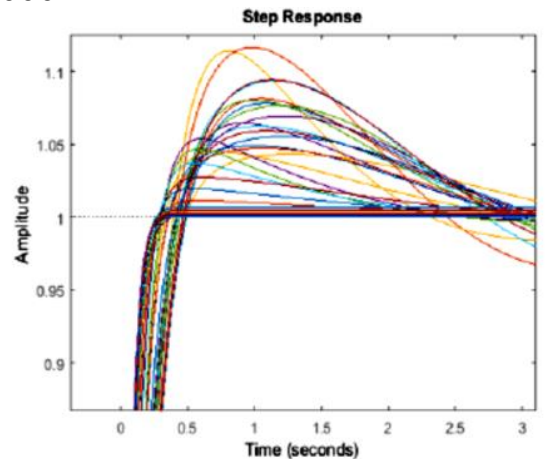

a)

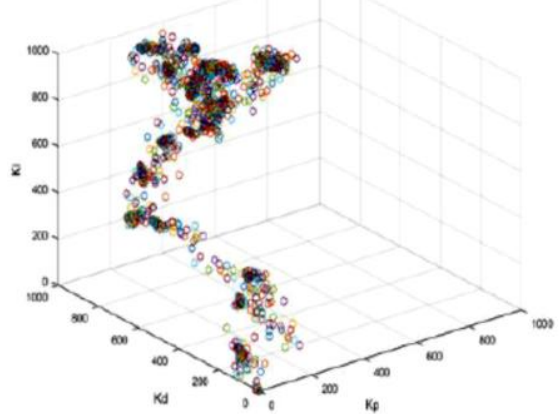

c)

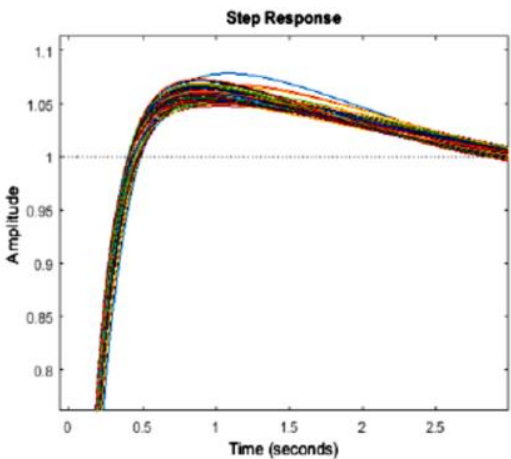

b)

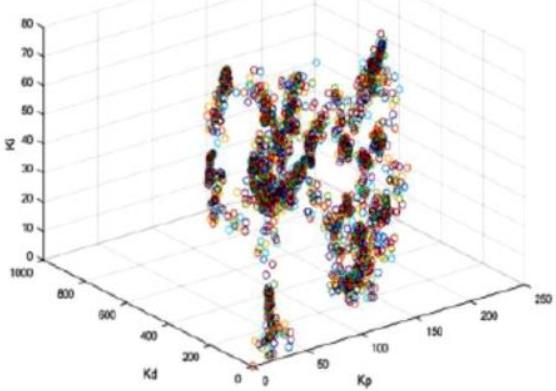

d)

Fig. 2. Optimization process: a) FA optimization process; b) BA optimization process; c) FA search space; d) BA search space. 


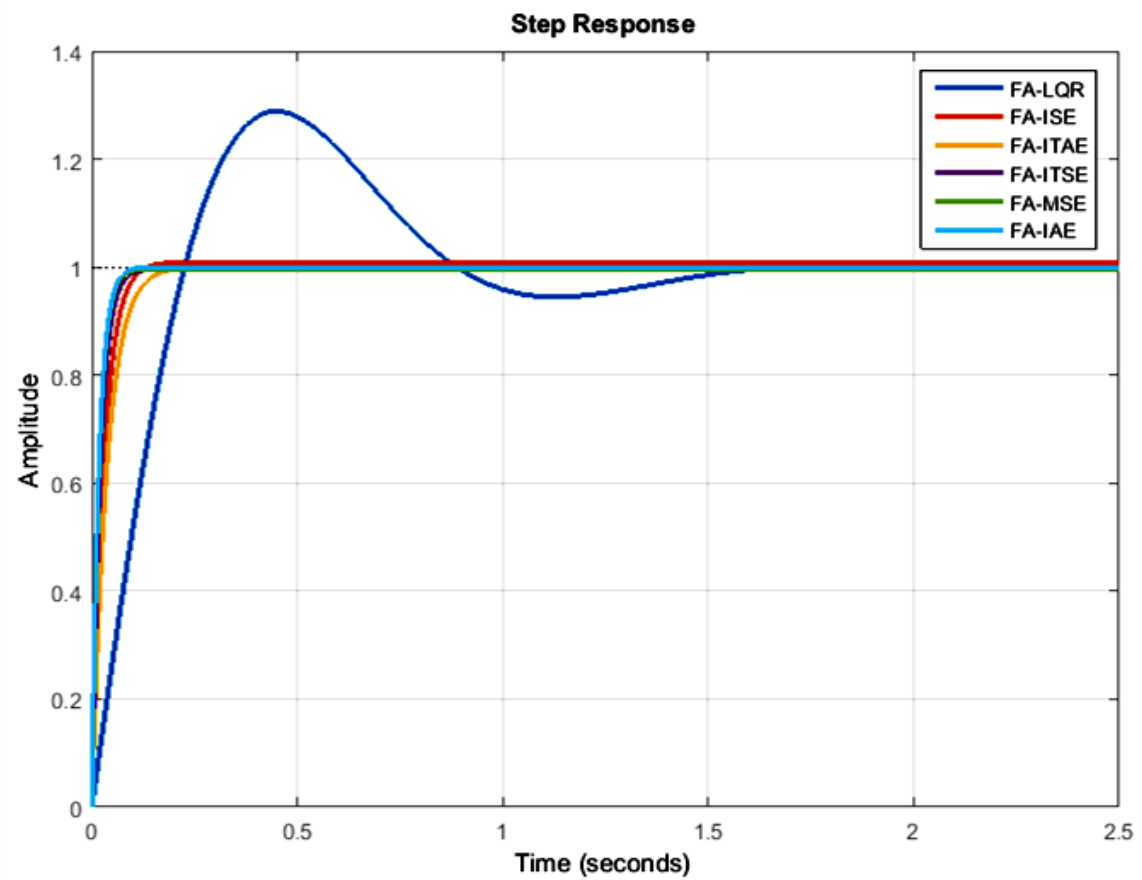

Fig. 3. System responses with FA-PID

\section{Conclusion}

With Simulated Annealing, particularly the Fast Annealing great performance of the system is achieved. With Boltzmann Annealing for 500 iterations the results were not satisfying. Regarding the objective functions, FA with IAE works slightly better compared to other objective functions and gives us the best results for 500 iterations. With settling time at 0.07 second, and steady state error of 0.0001 .

\section{References}

1. Asani, Z; Idrizi, F. A control system design for electromechanical system based on specified requirements. (2016). Page 96-105. Journal of Applied Sciences-SUT.

2. Chruszczyk, Ł. (2017). Applied Course of Basic Heuristic and Bio-Inspired Optimization Algorithms. Gliwice, Poland: Faculty of Automatic Control and Electronics.

3. Idrizi, F. (2012). Optimizimi i rrugës së instrumentit me teknika të inteligjencës artificiale te makina frezuese vertikale me CNC. Tiranë.

4. Ingber, L. Simulated Annealing: Practice versus Theory. Math. Comp. Modelling.

5. Kanthaswamy, G. Design of PID controller for dead-time systems using Simulated Annealing. Int. J. Automation and Control, Vol. 4, No. 4, 20.

6. Kendall, G. Simulated Annealing-AI Methods. Lecture Courses.

7. Mallick, S. STUDY OF THE DESIGN AND TUNING METHODS OF PID CONTROLLER 